\title{
Implementation of integrated vector management for disease vector control in the Eastern Mediterranean: where are we and where are we going?
}

\author{
A. Mnzava, ${ }^{1}$. Williams, ${ }^{2}$ R. Bos ${ }^{3}$ and M. Zaim ${ }^{4}$
}

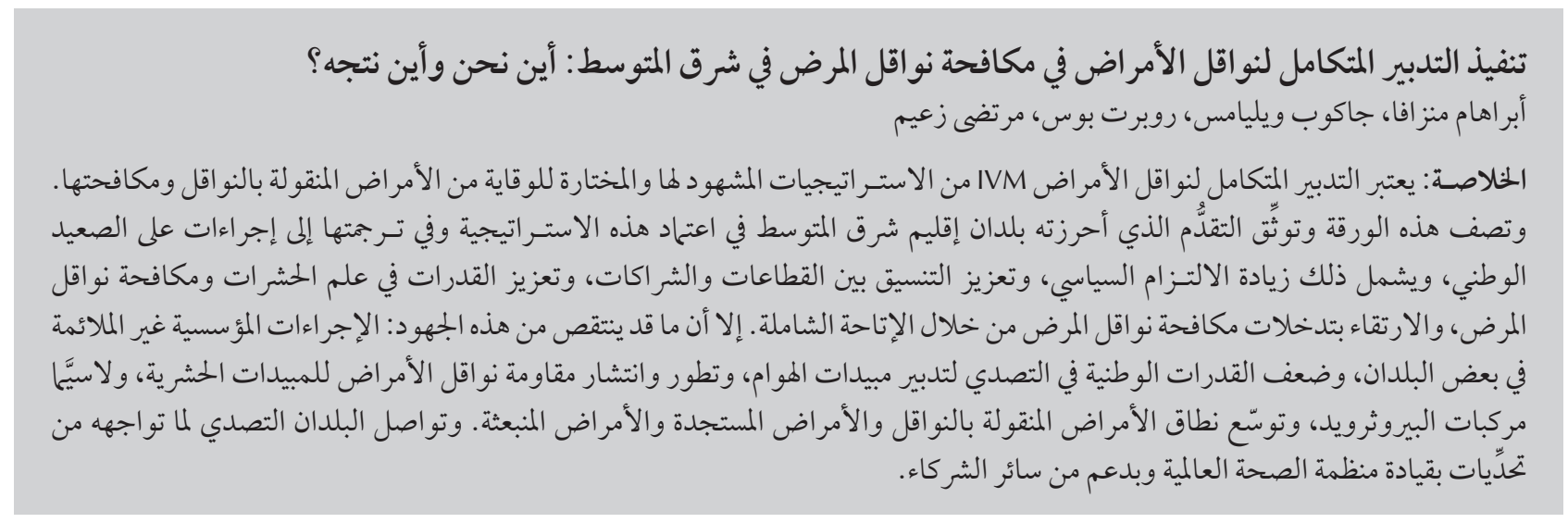

ABSTRACT Integrated vector management (IVM) is an acknowledged strategy of choice for the prevention and control of vector-borne diseases. The paper describes and documents the progress countries of the World Health Organization (WHO) Eastern Mediterranean Region have made in endorsing and translating the strategy into action at the national level. These include increased political commitment; strengthened intersectoral coordination and partnership; strengthened capacity in entomology and vector control; and scaling up of vector control interventions through universal access. These efforts, however, are compromised by inappropriate institutional arrangements in some countries; weak national capacities to address management of pesticides; development and spread of vector resistance to insecticides, including to pyrethroids; and the expansion of emerging and re-emerging vector-borne diseases. With WHO leadership and support from partners, countries continue to address these challenges head-on.

\begin{abstract}
Mise en œuvre de la gestion intégrée des vecteurs pour la lutte antivectorielle en Méditerranée orientale : état des lieux et orientations futures

RÉSUMÉ La gestion intégrée des vecteurs est une stratégie de choix reconnue pour la lutte contre les maladies à transmission vectorielle. Le présent article décrit et apporte la preuve des progrès réalisés par les pays de la Région OMS de la Méditerranée orientale dans l'adoption de cette stratégie et sa traduction en action à l'échelle nationale. Ces progrès comprennent notamment un engagement politique accru, une coordination et une collaboration intersectorielles intensifiées, des capacités renforcées en matière d'entomologie et de lutte antivectorielle et l'extension des interventions de lutte antivectorielle par l'intermédiaire de l'accès universel. Ces efforts, cependant, sont compromis par des dispositions institutionnelles inadaptées dans certains pays, des capacités nationales insuffisantes pour assurer la gestion des pesticides, l'apparition et la propagation de la résistance des vecteurs aux insecticides, en particulier aux pyréthroïdes, et aussi par la propagation des maladies émergentes et réémergentes à transmission vectorielle. Grâce au rôle moteur joué par l'OMS et à l'appui de leurs partenaires, les pays continuent à s'attaquer de front à ces difficultés.
\end{abstract}




\section{Introduction}

The World Health Assembly (WHA) is the policy-making body of the World Health Organization (WHO). Every year in May, Ministers of Health meet in Geneva to review policies and programmes of the Organization and to formulate new policies. These are submitted as draft resolutions for consensus building and adoption by the Assembly.

Resolution WHA 42.31 (1989) requested Member States, "to strengthen their capacity to ensure the implementation of effective vector control measures, and to develop and maintain, at all institutionallevels, the necessary human resources for planning and implementation of vector control interventions" [1]. The Resolution also requested the Director-General of WHO, "to ensure that the Organization's contribution to the development of safe and effective vector control methods was based on environmental considerations and was in line with the principles of sustainable development".

Eight years later, Resolution WHA 50.13 called on Member States, "to take steps to reduce reliance on insecticides for control of vector-borne diseases through promotion of integrated pest management approaches in accordance with WHO guidelines, and through support for the development and adaptation of viable alternative methods of disease vector control" and "to ensure that the use of DDT is authorized by governments for public health purposes only, and that, in those instances, such use is limited to government-authorized programmes that take an integrated approach." [2].

The call by the Assembly to promote an integrated management approach to vector control led to the formulation of a Regional Framework for integrated vector management (IVM) in WHO's African Region in 2001. [3]. This was followed in 2003 by the Eastern
Mediterranean Region [4]. In 2004 a global framework on IVM was developed [5] followed later by other Regions of WHO. Most recently, WHO issued a position statement (2008) [6] to ensure consensus on what constitutes IVM. The IVM development process was accelerated by the intergovernmental negotiations about a legally binding instrument aimed at reducing and eliminating compounds labeled as persistent organic pollutants (POPs), which went on between 1998 and 2001. These negotiations led to the Stockholm Convention on POPs, which, in reference to DDT, also pointed to IVM as the basis for reducing reliance on chemicals in public health programmes [7].

Today, IVM is acknowledged as the strategy of choice for the prevention and control of vector-borne diseases. For many of these diseases drugs or vaccines are available, but for some (dengue, Chagas disease) prevention and control has to rely exclusively on vector control interventions. In most other cases, vector control continues to complement immunization programmes, and case detection/drug treatment programmes, which are all faced with their own specific challenges and problems. Vector control therefore is sometimes the only tool for primary prevention and for control, sometimes a complementary component of an integrated disease control strategy and always a back up to ensure sustainability and resilience in achieved results.

While there are various landmark resolutions, frameworks and position statements, there has been no proper documentation of the on-going process itself and of progress attained so far. This paper attempts to review and document the process and progress of IVM implementation in countries of the WHO Region of the Eastern Mediterranean, to explore options for further strengthening of IVM in these countries, and to propose a way forward.

\section{Disease burden and the potential threat for expansion}

Vector-borne diseases, such as malaria, leishmaniasis, dengue, Rift Valley fever, lymphatic filariasis and African sleeping sickness, among others, constitute a major public health problem globally. They are responsible for almost $16 \%$ of the estimated global burden of all infectious diseases. Eleven per cent $(11 \%)$ of the global burden of vector-borne diseases is contributed by countries in the WHO Eastern Mediterranean Region, where only $8 \%$ of the global population lives [8]. This is also a region where slight changes in the ecology as a result of droughts, floods or agricultural land use can adversely affect the transmission dynamics of vector-borne diseases.

It is not surprising therefore that the Region has witnessed a significant re-emergence/emergence of vectorborne diseases in recent years. One of the most notable diseases is dengue. For example, since 1998, epidemics of dengue fever and dengue haemorrhagic fever have been reported from Somalia, Djibouti, Sudan, Pakistan, Saudi Arabia, and Yemen. In 2009 and first half of 2010, outbreaks of dengue fever and dengue haemorrhagic fever were reported from Saudi Arabia, Yemen, Pakistan and Sudan. Rift valley fever and chikungunya have also been reported in large numbers in recent years [9].

\section{Implementation of vector control in the Region}

During the 52nd Session of the WHO Regional Committee for the Eastern Mediterranean in 2005, Member States recognized the potential threat of emerging and re-emerging vector-borne diseases as well as their geographical and seasonal expansion. They also noted 
that there was a general weakness in national capacities to implement vector control in most countries of the Region. This was a result of inadequate national policies for vector control; insufficient resources allocated; lack of effective institutional arrangements; and duplication of effort among different programmes in the health sector.

The situation is also compounded by natural and man-made factors. These include: climate change leading to a rise in average temperatures and to extreme weather conditions, in turn resulting in droughts or floods; development projects changing the local hydrology, topography and land use patterns; uncontrolled urbanization; and population movement during conflict. In 2003, the WHO Regional Office for the Eastern Mediterranean arranged for country representatives and other experts and partners to review a draft Regional Framework on IVM [4]. This was further revised and finalized before being presented to the Regional Committee for discussion and endorsement.

Endorsement of
IVM as the regional
strategy for disease
vector control

In 2005, the WHO Regional Committee for the Eastern Mediterranean discussed the IVM framework and adopted resolution EM/RC52/R.6, which endorsed IVM as the strategy for the implementation of vector control in the Region [4]. The Committee acknowledged that the problem of vectorborne diseases was not solely due to technical and man-made factors, but also to a number of health system issues and that implementing IVM would go a long way to resolve such issues.

In the resolution, the Regional Committee requested Member States to "establish and strengthen national units for integrated vector management with adequate financial and human resources; establish a functional of intersectoral mechanism for the collaboration and coordination of all related sectors and identify needs, gaps and opportunities for vector control and develop national integrated vector management strategies and plans for all vector-borne diseases". WHO was requested, among other things, "to establish a regional diploma course in entomology; and to report regularly to the Regional Committee on the progress of the implementation of integrated vector management".

\section{Comprehensive \\ vector control \\ needs assessment}

\section{Development of tools for vector control needs assessment}

Clearly, to accomplish a paradigm shift in vector control, it is essential to identify the weaknesses in existing systems, and to ensure that the new approach addresses priority issues and will have a maximum impact in terms of reduced vector-borne disease burdens. WHO therefore developed an assessment tool which should be applied periodically as part of programme monitoring and evaluation. Moreover, vector control needs assessment is a prerequisite to the development of national integrated vector management strategies and plans. This is a process that allows countries to translate IVM into action at the national level. Member States and partners embarked on a rigorous process to develop, test and finalize this assessment tool and details can be found at: (http://www. emro.who.int/vbc/ivm_implementation_guidelines.htm).

The tool was used in 10 countries of the Region, 8 of which had the support of the United Nations Environment Programme/Global Environment Facility (Djibouti, Egypt, Islamic Republic of Iran, Jordan, Morocco, Sudan, Syrian Arab Republic and Yemen) while 2 used their national resources (Afghanistan and Oman). For each country, the tools were used to analyse the vectorborne disease situation, to describe the relevant policy framework for vector control, define the place and structure of the vector control programme/unit in the overall governance structure and in relation to the other programmes, evaluate the planning and implementation of vector control, the intersectoral coordination mechanisms for vector control at country level and the relevant community mobilization strategies for vector control. Details on the outcomes of these assessments can be seen at: (http://www.emro.who.int/vbc/ivm_ implementation_reports.htm).

The gaps and opportunities identified through this process highlighted the priority needs that should be addressed to achieve set targets for reducing the transmission potential and the burden of vector-borne diseases. This information was used to formulate national integrated vector management plans in the 10 countries, which comprise $80 \%$ of the high-risk countries for vector-borne diseases in the Region. Comprehensive vector control needs assessments still remain to be implemented in other priority countries of the Region, in particular Pakistan and Somalia.

\section{Results of comprehensive vector control needs assessment}

Not one of the 10 countries that undertook the assessment had a specific national policy for vector control of vector-borne disease prevention and control. This implied that no adequate resources were allocated to vector control. As a result of the exercise, these countries now have IVM as part of the national health policy.

Except in Morocco and Egypt, there was no vector-borne disease control unit in ministries of health, resulting in the absence of coordination of control 
efforts. In order to support and maintain the new IVM approach, such units needed to be established in ministries of health with clear roles and responsibilities and terms of reference for staff, coupled with appropriate incentives and a transparent performance appraisal process.

Until now only 4 of the 10 countries (Egypt, Jordan, Morocco and Sudan) have such a unit responsible for the control and prevention of all vector-borne diseases. In the 6 remaining countries, an attempt has been made to extend the IVM mandate to the national malaria control programme. While this is a step in the right direction, it limits the ability of the ministry of health and other sectors to act efficiently in the prevention and control of other vectorborne diseases. Unless there is strong coordination with the communicable disease surveillance department, vector control response to other vector-borne diseases other than malaria may be delayed when needed.

The need to strengthen national capacities through training (including career paths) and infrastructure development (insectaries, entomology laboratories and equipment) was also evident.

In terms of planning and scaling up ofvectorcontrolinterventionsthrough universal access, results showed a need to update the distribution of vectorborne diseases and their vector species so targeting of interventions could be improved: to develop and strengthen an integrated information system for vector control; to determine opportunities for synergistic use of interventions based on vector behaviour and ecology; to strengthen capacity to manage insecticides (including insecticide resistance monitoring and improved safety standards in management); and to strengthen coordination with ministries of agriculture and environment for adaptation, harmonization and enforcement of relevant policies.
The results confirmed that implementation of IVM depends on the strength of intersectoral coordination and collaboration, due to the potential impact of decisions and actions by other sectors on the transmission potential as well to the need to share scarce resources and avoid duplication of effort. It was clear from this assessment that the coordinating bodies for integrated vector management, when established in each country, would need legal recognition and incentives to sustain them. In parallel to this, community perceptions need to be identified, so awareness messages may result in changes in perceptions and behaviour to maximize the impact of interventions. A need was also documented to identify appropriate sources of information and local networks to allow empowerment of communities for vector control. The relevance of this, especially for dengue prevention, cannot be over-emphasized.

\section{Strengthening of national intersectoral coordination mechanisms}

One of the concrete outcomes of the national vector control needs assessments was the establishment of functional national intersectoral steering committees for IVM in each of the 10 countries. Representatives of this committee were drawn from different line ministries, academic institutions, the private sector and civil society. Table 1 shows the detailed composition of the committee members in each of the 10 countries assessed. These committees have clear terms of reference and well-defined responsibilities. The chairperson of this committee is the undersecretary of the ministry of health or his/her representative.

The committees are responsible for the implementation of the integrated vector management strategy, and its sustainability depends on the support of all key partners.
IVM implementation: strengthening entomology \& vector control capacities

ByadoptingResolutionEM/RC52/R.6, Member States committed themselves to scaling up appropriate vector control interventions in the context of the integrated vector management approach. They also recognized that countries lacked the capacity in entomology and vector control to implement integrated vector management effectively. In response to the Resolution, the Regional Office, in consultation with other leading international institutions, developed a regional postgraduate training programme in medical entomology and vector control. The robust curriculum includes a field training component, a unique feature of this programme. This one-year course was launched in August 2008 at the University of Gezira, Sudan in collaboration with WHO's Regional Office for the Eastern Mediterranean and other international institutions. These institutions include: the Vector Research Unit of the Pasteur Institute, Tehran, Islamic Republic of Iran; the London School of Hygiene and Tropical Medicine, London, United Kingdom; the National Institute for Communicable Diseases, University of Witwatersrand, Johannesburg, South Africa; the Vector Biology Research and Training Centre, Ain Shams University, Cairo, Egypt; the Liverpool School of Tropical Medicine, Liverpool, United Kingdom; the Istituto Superiori di Sanità,Rome,Italy; theInstitutde Recherche pour le Développement (IRD), France; the Centre for Research in Entomology, Cotonou (CREC), Cotonou, Benin; and, the National Malaria and Leishmaniasis Control Programme, Federal Ministry of Health, Khartoum, Sudan. Representatives from these institutions constitute an international steering committee to advise and coordinate the activities of this course. 


\begin{tabular}{|c|c|}
\hline Country & Sector involved \\
\hline Afghanistan & $\begin{array}{l}\text { Ministries of Health, Agriculture, Environment; municipalities; Environmental Protection Agency; } \\
\text { nongovernmental organizations; United Nations agencies }\end{array}$ \\
\hline Djibouti & Ministries of Health, Agriculture, Water and Irrigation, Environment and Djibouti municipality \\
\hline Egypt & $\begin{array}{l}\text { Ministries of Health and Population, Agriculture, Irrigation, Environment; municipalities; academic } \\
\text { and research institutions }\end{array}$ \\
\hline Islamic Republic of Iran & $\begin{array}{l}\text { Ministries of Health and Medical Education, Agriculture, Water and Irrigation; Environmental } \\
\text { Protection Agency; academic and research institutions }\end{array}$ \\
\hline Jordan & $\begin{array}{l}\text { Ministries of Health, Agriculture, Environment, Water and Irrigation; Jordan Valley and Greater } \\
\text { Amman municipalities; Ministry of Defence }\end{array}$ \\
\hline Morocco & Ministries of Health, Agriculture, Interior and Environment; research and academic institutions \\
\hline Oman & $\begin{array}{l}\text { Ministries of Health, Agriculture, Environment and Climatic Affairs; regional municipalities and } \\
\text { water resources; Ministry of Commerce and Industry }\end{array}$ \\
\hline Sudan & $\begin{array}{l}\text { Federal Ministry of Health (National Malaria Control Programme, Occupational Health } \\
\text { Department and State Ministries of Health); Ministries of Agriculture, Environment and Tourism, } \\
\text { Irrigation and Water Management; nongovernmental organizations; community-based } \\
\text { organizations (Sudanese Women Union) and the private sector, e.g. insecticidal treated nets/long- } \\
\text { lasting insecticidal nets; academic and research institutions }\end{array}$ \\
\hline Syrian Arab Republic & $\begin{array}{l}\text { Ministries of Health, Agriculture, Environment, Water and Irrigation; municipalities; academic } \\
\text { institutions }\end{array}$ \\
\hline Yemen & Ministry of Health and Population, Environment, Agriculture; municipalities, academic institutions \\
\hline
\end{tabular}

The same curriculum was adapted in Pakistan (hosted by Health Services Academy and Quaid-i-Azam University) and was launched in September 2009. With this progress, the Region should witness vector control units at all administrative levels of ministries of health and relevant health sectors being led by qualified staff who are not only able to plan and implement vector control interventions in the context of IVM, but who are also able to monitor and evaluate the impact of interventions.

\section{Scaling up vector control interventions in the context of IVM}

\section{LLINs implementation}

Prevention of vector-borne diseases is essential to the overall control strategy for these diseases. Based on proper epidemiological stratification and the demonstrated impact of interventions, indoor residual spraying of insecticides and the use of long-lasting insecticidal nets (LLINs) are the main vector control measures. Coupled with the availability of national strategies, resources were mobilized to scale up the implementation of universal access to LLINs. As a result, coverage of LLINs has increased over the past 3 years. Three programmes (Afghanistan, Somalia and southern Sudan) have made good progress in this respect despite health system weaknesses due to complex emergencies. These are countries that contribute to more than $60 \%$ of the vector-borne disease burden in the Region. At current rates of increase, approximately 36 million people will have access to LLINs by the end of 2010 and with appropriate communication and awareness strategies, use them. For details see Figure 1. More efforts, however, are needed in Pakistan to scale up coverage of this intervention.

\section{Insecticide resistance management}

In the past 2 years, insecticide resistance monitoring continued in countries in order to guide the selection of insecticides and to facilitate the development of management strategies to delay and mitigate the consequences of resistance. In Morocco, the main malaria vector species, Anopheles labranchiae, was reported resistant to DDT and a national policy to switch to pyrethroids was advocated (Ministry of Health, Morocco, unpublished report). In parts of Al-Dahira region, Oman, An. stephensi was reported resistant to temephos and suitable alternatives for biological control are being applied (Ministry of Health, Oman, unpublished report).

In Sudan, for the first time in the Region, the local malaria vector species An. arabiensis was reported resistant to pyrethroids [10-12], the insecticide of choice for indoor residual spraying and for treating bednets. In the same area the vector is also resistant to DDT (an organochlorine) and to malathion (an organophosphate). Switching to bendiocarb (a carbamate) is the remaining alternative; however, bendiocarb is not only expensive (it requires 2 cycles of spraying), it also cannot be used to treat mosquito nets. A recent assessment has indicated that the vector resistance to pyrethroids has not only increased but also expanded to other geographical 


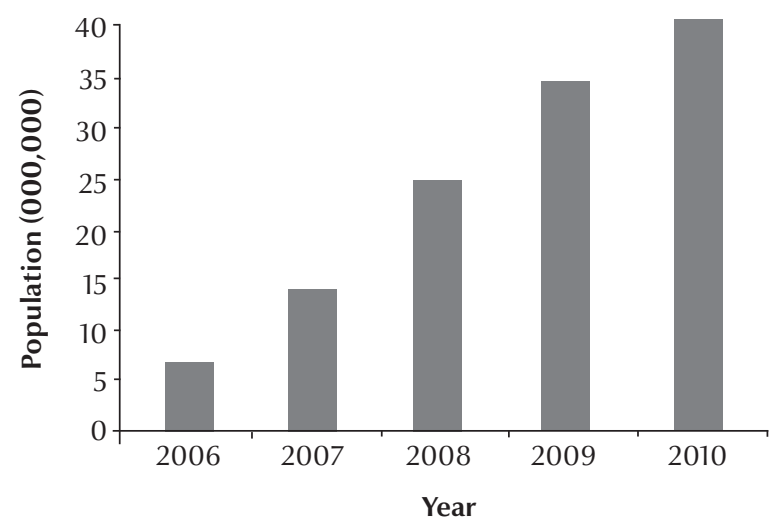

Figure 1 Population protected with long-lasting insecticidal nets from 2006 to 2010 in the Eastern Mediterranean Region

areas despite a management strategy in place. The inability of the control programme at the periphery level to sustain 2 rounds of carbamate spraying has been one of the reasons.

Sound management of publichealth pesticides as a key component of IVM is a major problem in countries of the Region - including proper handling, import, supply, transport, storage, use and disposal of pesticide-related waste. A life-cycle approach for pesticides management is therefore recommended [13].

\section{Challenges \& constraints in implementation of IVM}

Most of the countries in the WHO Eastern Mediterranean Region that are endemic for vector-borne diseases have integrated vector management plans and strategies and are currently implementing them; however, they still face a number of challenges and constraints. First is the lack of commitment to translate IVM into a national health policy. Second, the institutional arrangements for IVM continue to be inappropriate in the majority of countries. What some countries have done (with the exception of Egypt, Jordan, Morocco and Sudan) is to extend the mandate of existing disease-specific programmes (e.g. malaria) to include other vectorborne diseases. This approach fails to appreciate the diversity and complexity of vector-borne diseases and their requirements for control and prevention, and has not helped in generating additional national resources for vector control. Third, countries with a low vector-borne disease burden have not yet used the opportunity to implement IVM, despite the fact that vector-borne diseases are expanding to new areas and countries.

In terms of scaling up vector control interventions, the biggest challenge has been the lack of documentation on the appropriateness of vector control interventions in responding to emerging and re-emerging vector-borne diseases. Following outbreaks of dengue in Pakistan, Saudi Arabia, Sudan and Yemen, sandfly fever in Lebanon and Rift Valley fever in Somalia and Sudan in the past few years, vector control interventions (mainly space spraying) were deployed late and therefore the impact was difficult to quantify. Since these interventions are expensive, it is important that their appropriateness be assessed through operational research. Moreover, the establishment of a vector control unit (as part of the national integrated vector management strategy) for all vector-borne diseases in the ministry of health and close coordination with the department of communicable dis- ease surveillance would facilitate rapid response.

\section{Opportunities: the way} forward with IVM

As mentioned before, The Global Fund to Fight AIDS, Tuberculosis and Malaria provides support for malaria vector control in the form of tangible items such as LLINs, insecticides, spraying equipment as well as infrastructural support. Moreover, the Bill and Melinda Gates Foundation has not only challenged the vector control fraternity with setting a goal for elimination of malaria, the Foundation has also promised to provide support to achieve that goal. Never in the history of vector control has there been such an opportunity for funding as this [14]. The Region has made progress in IVM implementation - laying down the foundation of national systems to deliver vector control interventions - and the countries should seize this funding opportunity. The Region on the other hand is also spearheading the malaria elimination initiative globally [15]. As this is currently feasible in countries with low malaria transmission intensity $[16,17]$, it would be prudent to direct these resources to areas of high disease vector transmission intensity. These are areas that contribute to approximately more than $60 \%$ of the burden due to vector-borne diseases in the Region and scaling up of vector control interventions would benefit more than one vector-borne disease.

In conclusion, therefore, the implementation of integrated vector management in countries of the WHO Eastern Mediterranean Region has progressed well. The sustainability of the established national intersectoral coordination mechanisms, however, cannot be guaranteed without firm commitment from the different sectors involved. Countries that have not initiated this process because vector-borne diseases 
are not currently a national public health problem should be encouraged to do so. They need to strengthen their capacity for management of public health pesticides as a key component of IVM. Plans to strengthen capacity in vector control and entomology have begun to bear fruits. It is expected that at least each country will have a well trained entomologist/vector control focal point who through appropriate mentorship will guide the planning and implementation of vector control in the context of IVM in the country. It is also expected that the use of vector control tools that rely heavily on the use of insecticides will be based more on evidence, including vector susceptibility status. Monitoring and management of vector resistance to insecticides is therefore critical and strengthening this capacity in the Region is a priority and is currently being supported.

\section{Acknowledgements}

The authors wish to thank the country teams who collected the information using the vector control needs assessment tools. Part of that information has been summarized by the authors and used in this publication. Financial support was obtained from the United
Nations Environment Programme (UNEP) and the Global Environmental Facility (GEF). The authors are grateful for the support from these organizations.

\section{Declaration of conflict of interest}

AM, JW, RB and MZ contributed in developing and field-testing the vector control needs assessment tools. AM worked with countries to analyse the country needs assessment reports and drafted this manuscript. The authors declare no competing interests.

\section{References}

1. World Health Assembly Resolution WHA42.31. Control of disease vectors and pests. In: Forty-second World Health Assembly, Geneva 8-19 May 1989. Geneva, World Health Organization, 1989

2. World Health Assembly Resolution WHA50.13. Promotion of chemical safety, with special attention to persistent organic pollutants. In: Fiftieth World Health Assembly, Geneva 5-14 May 1997. Geneva, World Health Organization, 1997.

3. Integrated vector management: strategic framework for the African Region 2004-2010. Harare, World Health Organization Regional Office for Africa, 2002.

4. Integrated vector management: strategic framework for the Eastern Mediterranean Region 2004-2010. Cairo, World Health Organization Regional Office for the Eastern Mediterranean, 2004.

5. Global strategic framework for integrated vector management. Geneva, World Health Organization, 2004 (WHO/CDS/CPE/ PVC/2004.10)

6. Integrated Vector Management, Position Statement. Geneva, World Health Organization, 2008 (WHO/HTM/NTD/ VEM/2008.2).

7. The use of DDT in malaria vector control, Position Statement. Geneva, World Health Organization, 2007 (www.who.int/ entity/malaria/publications/atoz/who_htm_gmp_2007/en/, accessed 10 April 2011).

8. Vector-borne diseases: addressing a re-emerging public health problem. Cairo, World health Organization Regional Office for the Eastern Mediterranean, 2005 (EM/RC52/3).

9. Growing threat of viral haemorrhagic fevers in the Eastern Mediterranean Region: a call for action. Cairo, World Health Organi- zation Regional Office for the Eastern Mediterranean, 2007 (EM/RC54/4).

10. Matambo TS et al. Insecticide resistance in the malarial mosquito Anopheles arabiensis and association with the $k d r$ mutation. Journal of Medical and Veterinary Entomology, 2007, 21:97-102.

11. Abdalla $\mathrm{H}$ et al. Insecticide susceptibility and vector status of natural populations of Anopheles arabiensis from Sudan. Transaction of the Royal Society of Tropical Medicine and Hygiene, 2008, 102:263-271.

12. Ranson et al. Insecticide resistance in Anopheles gambiae: data from first year of a multi-country study highlight the extent of the problem. Malaria Journal, 2009, 8:299.

13. Guidelines on the management of public health pesticides. Geneva, World Health Organization, 2003 (www.who.int/entity/ malaria/publications, accessed 10 April 2011).

14. Snow RW et al. International funding for malaria control in relation to population at risk of stable Plasmodium falciparum transmission. PLoS Medicine, 2008, 5(7):e142.

15. Malaria elimination in the Eastern Mediterranean Region: vision, requirements and strategic outline. Cairo, World Health Organization Regional Office for the Eastern Mediterranean, 2008 (EM/RC55/9).

16. Lines J, Schapira A, Smith T. Tackling malaria today. British Medical Journal, 2008, 337:a869.

17. Tanner M, Hommel M. Towards malaria elimination - a new thematic series. Malaria Journal, 2010, 9:24. 